vene. One of these is undoubtedly the behaviour of the pigment system concerned in the initial act of light perception. The discovery of this, the phytochrome system, by Borthwick's group at the U.S. Department of Agriculture is a classic of plant physiological research, and it receives its due treatment in this book.

The view that the perception of the photoperiodic stimulus in the leaf leads to the synthesis of a hormoneChailachjan's florigen-which is afterwards translocated to the apex where the response occurs has long been generally accepted. Salisbury is firmly wedded to it, and he reviews much of the circumstantial evidence bearing on synthesis and translocation. That a hormone is concerned can barely be doubted in the face of so much evidence; yot florigen continues to defy isolation. Salisbury interprets the fact that amino-acid analogues inhibit synthesis as indicating that the hormone may be a peptide.

The final chapter of the book is concerned with the action of the hormone in the meristem. That its effect is to change patterns of gene transcription has long been evident on general genetical grounds, and it is satisfactory that recent work with anti-metabolites, some of which is reviewed in the book, does show that the flowering stimulus is 'perceived' only in apices where there is an active nucleic acid synthesis.

The book is written in a style which varies from the coldly professional to the matey, but the text is readable enough. It is well illustrated, although some of the graphs are difficult to evaluate because information about some features of experimental design, for example, numbers of replicates, is lacking. Perhaps this is because the author eschews statistics in the evaluation of Xanthium experiments on the grounds that differences are generally clear cut-"the trends are quite clear", although "the experimental points (the actual data) do not always fall upon the curves as drawn".

Production is good, but the book is distinctly expensive for a British publication. J. Heslop-Harrison

\section{USES OF PHYTOCHEMISTRY IN TAXONOMY}

\section{Chemical Plant Taxonomy}

Edited by T. Swain. Pp. ix +543. (London : Academic Press, Inc. (London), Ltd. ; New York: Academic Press, Inc., 1963.) $110 s$.

AXONOMY serves the twin functions of classification and phylogeny. It has long been recognized that even the most detailed morphological and histological investigations, while completely adequate as a means of classification and identification, can only serve as a very general guide in establishing phylogenetic relationships. Taxonomists are therefore very alive to the need for exploring the possibilities afforded by more sensitive methods. Of the ancillary techniques that have become available, plant taxonomy has derived most benefit from phytochemistry and experimental genetics, although the severe limitations imposed by the ability of taxa to intercross restrict the usefulness of the latter to disappointingly narrow fields of enquiry, mostly at the species-level. Phytochemistry is free from this restriction and can be applied over the entire range of living organisms, but, as is clearly shown by A. J. Birch and by R. Hegnauer in this volume, the great divorsity of interwoven pathways in biogenesis can frequently render studies on the distribution of plant products completoly uninformative, and sometimes misleading, as a taxonomic method, unless homologous, gene-controlled steps in the biosynthesis of the compounds under investigation are also critically established.

Chemical Plant Taxonomy is the first attempt to convey the scope and analyse the application of phytochemistry in plant taxonomy. All the contributors emphasize both the inadequacy of present knowledge of plant chemistry and the dangers inherent in attaching too much weight to patterns of distribution of end-products of biosynthesis in discussions on phylogeny. Nevertheless, the book indicates clearly the considerable potential of phytochemical methods when proper ly applied to taxonomic problems, and conveys the immens $\theta$ interest that has emerged in the chemistry of natural products with the recent development of rapid and powerful techniques of plant analysis. Of the sixteen chapters contributed by various authors, six deal with general topics covering methods of classical plant taxonomy (S. M. Walters), species concepts (J. Heslop-Harrison), history of chemical taxonomy (R. D. Gibbs), factors affecting the production of natural products (H. Flück), biosynthetic pathways (A. J. Birch) and the usefulness of the flavonoid constituents in plant taxonomy (E. C. Bate-Smith). Four chapters deal with aspects of the chemistry of deíned taxonomic groups: some aspects of chemotaxonomy (H. Erdtman), chemical taxonomy of acetylenic compounds (N. A. Sørensen), taxonomic significance of alkaloids (R. Hegnauer) and the distribution of alkaloids in the Rutaceae (J. R. Price). The remaining six chapters are devoted to accounts of the distribution of certain groups of natural products in the plant kingdom. These include the alkanes (G. Eglinton and R. J. Hamilton), fatty acids in plant lipids (F. B. Shorland), aliphatic polyols and cyclitols (V. Plouvier), glycosides (R. Paris), anthocyanins (J. B. Harborne), and sulphur compounds (A. Kjaer).

As might be expected from authors who are active in research, each subject is presented in great detail, and the taxonomic implications are generally candidly discussed. Those who might have expected decisive solutions to long-standing evolutionary problems will be disappointed by the rather tentative taxonomic indications that have so far emorged from the investigations; but, as is repeatedly emphasized by the authors, the present investigations on plant products are only just a beginning and much more intensive work needs to be done on the distribution of carefully chosen compounds within defined taxonomic groups, before the full contribution of chemistry to plant taxonomy can be objectively assessed. It is immediately clear from the great deal of effort that underlies the present exploratory phase of chemotaxonomy what a tremendous task this will be. However, if some of the investigations presented here, such as those on the chemistry of the Pinales, on the alkaloids of the Rutaceae, and on the glycosidic pattorns of anthocyanins, may bo taken as indicative of future promise, the effort is bound to be taxonomically rewarding.

Considering the vast number of botanical names and of organic chemicals mentioned, tho book is remarkably free of printing errors, and the standard of production and of editing is high throughout. The appendix of orders and families within the plant kingdom provides valuable assistance in following the discussions on taxonomic implications, and the indexes of genera and species and of chemical compounds make the book valuable to both chemists and botanists as a work of referonce on the distribution of a wide range of natural products.

\section{W. WILliams}

\section{MARINE MICROBIOLOGY}

\section{Symposium on Marine Microbiology}

Compiled and edited by Carl H. Oppenheimer. Pp. xviii +769 . (Springfield, Illinois: Charles C. Thomas, Publishers, 1963.) 22.50 dollars.

$\mathrm{M}$ ARINE microbiology, as S. C. Rittenberg in this volume suggests, is concerned more with those marine processes which are effected by microbial ageney than merely with the affairs of micro-organisms that 